\title{
Predictors of the need for laminectomy after indirect decompression via initial anterior or lateral lumbar interbody fusion
}

\author{
Daehyun Park, MD, ${ }^{1}$ Praveen V. Mummaneni, MD, ${ }^{2}$ Ratnesh Mehra, DO, ${ }^{2}$ Yonguk Kwon, MD, \\ Sungtae Kim, MD, ${ }^{3}$ Hui Bing Ruan, MD, ${ }^{4}$ and Dean Chou, MD ${ }^{2}$
}

'Department of Orthopedic Surgery, Inje University Busan Paik Hospital, Busan, Korea; ${ }^{2}$ Department of Neurosurgery, University of California, San Francisco, California; ' ${ }^{D}$ epartment of Neurosurgery, Inje University Busan Paik Hospital, Busan, Korea; and ${ }^{4}$ Department of Orthopedic Surgery, The Fourth Affiliated Hospital of Nan Chang University, Nanchang, China

\begin{abstract}
OBJECTIVE The goal of this study was to evaluate factors that are associated with the need for additional posterior direct decompressive surgery after anterior lumbar interbody fusion (ALIF) or lateral lumbar interbody fusion (LLIF).

METHODS Eighty-six adult patients who underwent ALIF or LLIF for degenerative spondylolisthesis and foraminal stenosis were enrolled. Patient factors (age, sex, number of surgery levels, and visual analog scale [VAS] score for leg and back pain); procedure-related factors (cage height and lordosis); and radiographic measurements (disc height [DH]; foraminal height [FH], foraminal area [FA], central canal diameter [CCD], and facet joint degeneration [FD]) were analyzed. All patients underwent staged surgery on 2 different days, with the anterior portion first, followed by the posterior portion. RESULTS Of 86 patients, 62 underwent posterior decompression and 24 had no posterior decompression. There were no significant differences between groups with regard to age, sex, preoperative VAS score for back pain, cage height, cage angulation, preoperative $\mathrm{DH}, \mathrm{FH}, \mathrm{FA}, \mathrm{CCD}$, and FD $(\mathrm{p}>0.05)$. The group that underwent posterior decompression showed statistically different numbers of treated segments (1.92 vs $1.21, p<0.01$ ), preoperative VAS leg score (7.9 vs 6.3 ), symptom duration (14.2 months vs 9.4 months), postoperative $\mathrm{DH}$ improvement (61.3\% vs $96.2 \%$ ), postoperative $\mathrm{FH}$ improvement (21.5\% vs $32.1 \%)$, postoperative FA improvement ( $24.1 \%$ vs $36.9 \%)$, and cage height minus preoperative $\mathrm{DH}(5.3 \mathrm{~mm}$ vs $7.5 \mathrm{~mm}$ ) compared with the nondecompression group.
\end{abstract}

CONCLUSIONS There appears to be some correlation between the need for posterior decompression and the number of treated segments, VAS leg scores, symptom duration, FH, FA, and difference between the cage height and preoperative $\mathrm{DH}$. In selected patients undergoing staged surgery, indirect decompression without direct decompression may be a reasonable option in treating degenerative spinal conditions.

https://thejns.org/doi/abs/10.3171/2019.11.SPINE19314

KEYWORDS indirect decompression; anterior lumbar interbody fusion; ALIF; lateral lumbar interbody fusion; LLIF; oblique lateral interbody fusion; OLIF; extreme lateral interbody fusion; XLIF

$\mathrm{D}$ EGENERATION of the lumbar spine is one of the most common problems in the aging population. It can cause disabling back pain, radiculopathy, and claudication, thereby decreasing quality of life. ${ }^{2,16}$ Interbody lumbar fusion is an effective method for symptom alleviation by stabilizing the painful motion segment, decompressing the nerve root via foraminal height $(\mathrm{FH})$ restoration, and tenting the ligamentous structures to partially alleviate central stenosis. ${ }^{8}$ Interbody lumbar fusions can be done via posterior, anterior, or lateral approaches. Each approach has its advantages and disadvantages in terms of fusion rate, $\mathrm{FH}$ restoration, and lordosis restoration. ${ }^{11}$ In addition, each approach has evolved a minimally invasive corollary, potentially minimizing approach-related morbidity.

The posterior approach has the advantage of safety, familiarity to spine surgeons, and direct decompression of the neural elements. ${ }^{11}$ The posterior approach (usually

ABBREVIATIONS ADH = anterior disc height; $A$ LIF = anterior lumbar interbody fusion; $C C D=$ central canal diameter; $D H=$ disc height; $F A=$ foraminal area; FD = facet joint degeneration; $\mathrm{FH}$ = foraminal height; LLIF = lateral lumbar interbody fusion; $\mathrm{PDH}=$ posterior disc height; TLIF = transforaminal lumbar interbody fusion; VAS = visual analog scale; XLIF = extreme lateral interbody fusion.

SUBMITTED March 27, 2019. ACCEPTED November 5, 2019.

INCLUDE WHEN CITING Published online January 24, 2020; DOI: 10.3171/2019.11.SPINE19314. 
transforaminal lumbar interbody fusion [TLIF]) affords the ability to perform direct neural decompression during the surgery. However, the open posterior approach carries the morbidity of paraspinal musculature injury and potential disruption of posterior tension band. The anterior and lateral lumbar interbody approaches afford a larger interbody graft footprint and cage height options compared to the posterior approach, but there is no direct decompression with the anterior or lateral approaches alone. ${ }^{11}$ By performing an anterior lumbar interbody fusion (ALIF) or lateral lumbar interbody fusion (LLIF), indirect decompression may be achieved through disc height (DH) restoration, $\mathrm{FH}$ restoration, foraminal area (FA) increase, and distraction of the posterior longitudinal ligament. ${ }^{14}$ Many studies have confirmed the power of interbody grafting, reporting improvements in postoperative $\mathrm{DH}, \mathrm{FH}, \mathrm{FA}$, and central canal diameter (CCD) after indirect decompression. ${ }^{7,9,10,12,18}$ In addition, many studies have reported that the increase in FH and FA correlates with improved clinical outcomes. ${ }^{7,12,18}$

Despite the power of the interbody fusion, it remains unclear if indirect decompression alone is enough to completely alleviate radiculopathy and claudication symptoms; the rate of additional posterior laminectomy after indirect decompression has been reported to vary from $0 \%$ to $60 \% .{ }^{11-14}$ Thus, the efficacy of indirect decompression remains uncertain. Although many would agree that direct posterior decompression is necessary in the presence of severe central canal stenosis, there are no clear guidelines on which patients require additional posterior direct decompression after ALIF or LLIF. The purpose of this study is to evaluate factors that are associated with the need for additional posterior direct decompression after ALIF or LLIF in patients with degenerative lumbar spinal conditions.

\section{Methods}

\section{Patients and Surgery}

Between January 2010 and August 2017, patients who underwent 1-3 levels of ALIF or LLIF by 2 senior spine surgeons at a single North American spine center were enrolled. Institutional review board permission was obtained. Surgical indications were symptoms of leg pain, leg numbness, neurogenic claudication, and severe lowback pain that did not improve with adequate conservative treatment. Patients with degenerative lumbar conditions such as up-down foraminal stenosis causing radiculopathy or spondylolisthesis (Meyerding grades 1 and 2) as diagnosed on radiographs, CT scans, and MR images were included in this study. Patients with adult spinal deformity or scoliosis, infection, fracture, spinal tumor, prior lumbar surgery, or significant neurological deficit (3/5 or weaker) were all excluded. Moreover, cases in which direct posterior decompression was planned on the same day were also excluded. All patients initially underwent ALIF or LLIF on one day and were allowed to recover in the hospital as inpatients and to ambulate. Subsequently, the second stage of posterior surgery was performed on another day during the same hospitalization. Postoperative visual analog scale (VAS) score for leg pain (VAS leg) was assessed

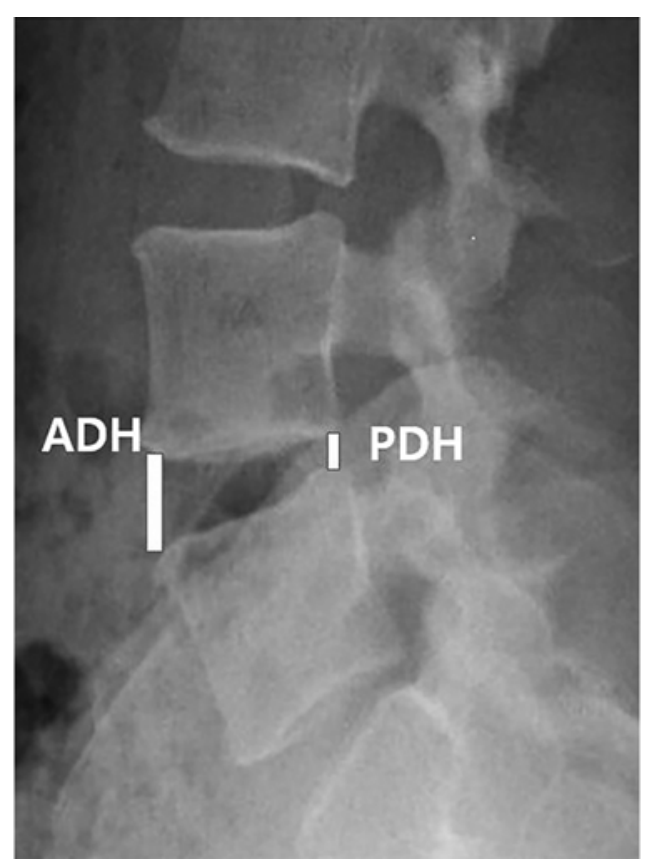

FIG. 1. The DH was calculated as the mean value of $A D H$ and $P D H$ on the radiograph.

and decompression was not performed when leg pain improved more than 50\%. Posterior surgery consisted of percutaneous screw fixation without decompression (nondecompression group) and additional posterior direct decompression with pedicle screw fixation (decompression group). Stand-alone ALIF cases were included in the nondecompression group. Factors such as sex, age, duration of symptoms (months), preoperative VAS score for back pain (VAS back), and VAS leg score were assessed. In addition, the number of fusion levels, cage height, and cage lordosis were also recorded. Finally, VAS back and leg scores were assessed at 1 year after the second surgery.

\section{Radiographic Evaluation}

We measured the DH, FH, FA, and CCD before the first staged surgery using radiographs, CT scans, and MR images. All postoperative radiographic measurements were collected from plain radiographs after the first surgery and before the second posterior surgery. DH was calculated as the mean value of anterior disc height (ADH) and posterior disc height (PDH). ADH was measured as the distance between the 2 endplates at the anterior aspect of disc space, and PDH was measured as the distance between the 2 endplates at the posterior-most portion (Fig. 1). FH was measured as the distance between the inferior pedicle and the superior pedicle of the level below (Fig. 2). ${ }^{3}$ FA was measured by using a digitalized tool measuring the area in the picture archiving and communication system (PACS) (Fig. 3). CCD was measured as the distance from the midlevel of disc space to the ligamentum flavum on the midsagittal plane on MRI (Fig. 4). The degree of facet joint degeneration (FD) was classified as grade $0-3$ according to Pathria et al.'s grading system by using the preoperative CT scans. ${ }^{15}$ 


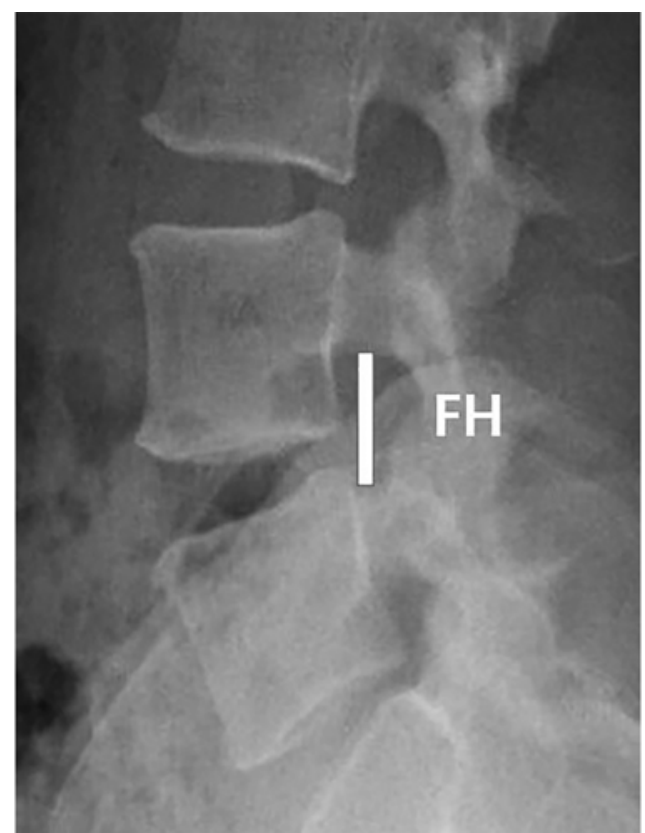

FIG. 2. The FH was measured as the distance between the inferior pedicle and the superior pedicle of the level below it on the radiograph.

\section{Statistical Analysis}

A paired t-test was used. The statistical program used was SAS software (version 9.4, SAS Institute). A p value $<0.05$ was considered statistically significant in analysis. Continuous variables are presented as the mean $( \pm \mathrm{SD})$.

\section{Results}

After exclusions for deformity, prior lumbar surgery, tumor, trauma, infection, and major surgery-related complications after the surgery, a total of 86 patients were enrolled who underwent ALIF or LLIF. Sixty-two patients underwent additional posterior decompression during their second stage, and 24 patients had no posterior decompression. The second posterior staged surgery was performed on average $2.8( \pm 11.2)$ days after the ALIF or LLIF. In the decompression group the mean duration between the first and second surgery was $2.7( \pm 11.3)$ days, and in the nondecompression group it was $2.9( \pm 2.1)$ days. There was no significant difference between the 2 groups with regard to the mean duration between the first and second surgery. The VAS leg score after the first surgery was $3.4( \pm 2.8)$ in the decompression group and $2.2( \pm 1.8)$ in the nondecompression group. There was a significant difference $(\mathrm{p}=0.01)$.

The mean age of the decompression group was $62.7( \pm$ 12.8 ) years, with 15 men and 47 women. The mean duration of symptoms was $14.2( \pm 10.5)$ months. The mean preoperative VAS back score was $7.2( \pm 2.8)$ and the VAS leg score was $7.9( \pm 2.1)$. The mean age of the nondecompression group was $64.2( \pm 14.1)$ years. The mean duration of symptoms was $9.4( \pm 9.5)$ months. The mean preoperative VAS back score was $6.9( \pm 3.1)$ and the VAS leg score was $6.3( \pm 2.7)$. There were significant differences

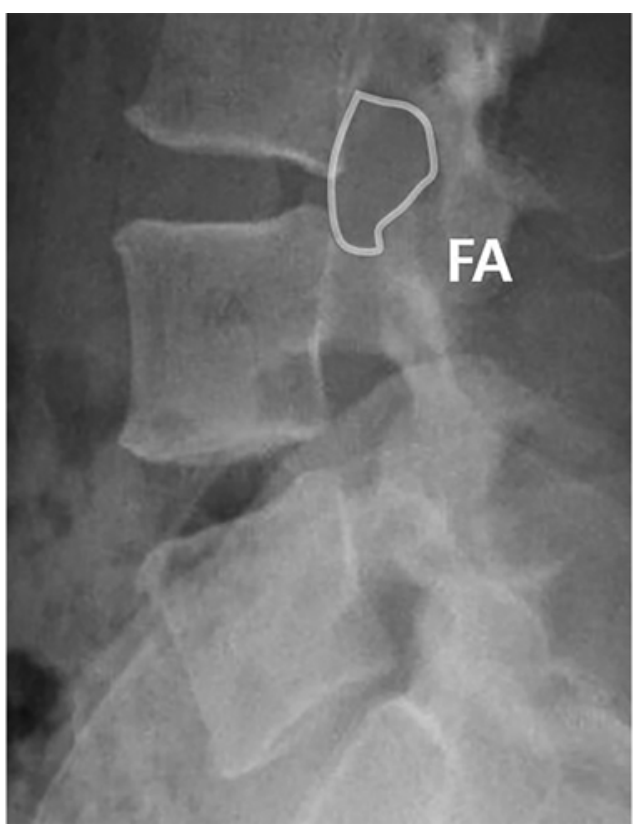

FIG. 3. The FA was measured by using a digitalized tool measuring the area on the radiograph.

between the 2 groups with regard to the mean duration of preoperative symptoms and preoperative VAS leg scores $(\mathrm{p}<0.05)$ (Table 1).

In the decompression group, there were 23 single-level and 39 multilevel fusions. Within this group, the mean number of fusion levels was 1.92 . The mean cage height was $15.3( \pm 7.7) \mathrm{mm}$, and the mean cage lordosis was $15.9^{\circ}$ $\left( \pm 7.9^{\circ}\right)$. In the nondecompression group, 20 single-level and 4 multilevel fusions were performed, and the mean number of fusion levels was 1.21. The mean height of the

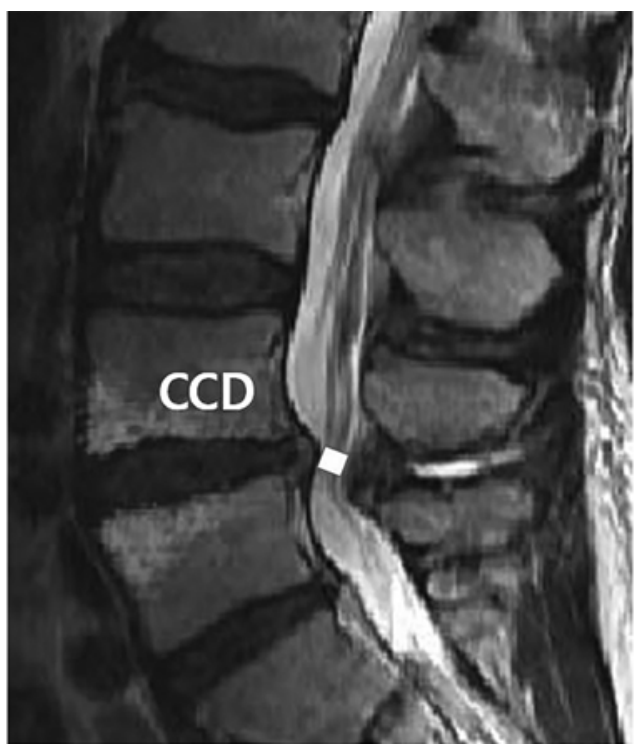

FIG. 4. The CCD was measured as the distance from the midlevel of disc space to the ligamentum flavum on the MR image. 
TABLE 1. Demographic characteristics and patient-related factors

\begin{tabular}{lccc}
\hline \multicolumn{1}{c}{ Characteristic } & Decompression & Nondecompression & $\begin{array}{c}\mathrm{p} \\
\text { Value }\end{array}$ \\
\hline No. of patients & 62 & 24 & \\
\hline Age in yrs & $62.7 \pm 12.8$ & $64.2 \pm 14.1$ & 0.32 \\
\hline Sex & $15 \mathrm{M}, 47 \mathrm{~F}$ & $6 \mathrm{M}, 18 \mathrm{~F}$ & 0.22 \\
\hline $\begin{array}{l}\text { Symptom duration, } \\
\text { mos }\end{array}$ & $14.2 \pm 10.5$ & $9.4 \pm 9.5$ & 0.01 \\
\hline VAS back score & $7.2 \pm 2.8$ & $6.9 \pm 3.1$ & 0.18 \\
\hline VAS leg score & $7.9 \pm 2.1$ & $6.3 \pm 2.7$ & 0.01 \\
\hline
\end{tabular}

Unless otherwise indicated, values are expressed as the mean \pm SD.

cage was $14.6( \pm 4.6) \mathrm{mm}$, and the mean cage lordosis was $15.1^{\circ}\left( \pm 5.1^{\circ}\right)$. There were significant differences in the mean number of fusion levels between the decompression and the nondecompression groups $(\mathrm{p}<0.05)$ (Table 2).

With regard to preoperative measurements, in the decompression group the mean DH was $5.9( \pm 6.3) \mathrm{mm}, \mathrm{FH}$ was $15.7( \pm 6.2) \mathrm{mm}$, FA was $103.3( \pm 52.1) \mathrm{mm}^{2}$, and CCD was $7.3( \pm 6.2) \mathrm{mm}$. The mean value of FD was 2.3 \pm 1.3 . In the nondecompression group, the preoperative mean DH was $6.2( \pm 5.3) \mathrm{mm}$, FH was $16.2( \pm 5.9) \mathrm{mm}$, FA was $110.7( \pm 56.2) \mathrm{mm}^{2}$, and CCD was $7.8( \pm 6.9) \mathrm{mm}$. The mean value of FD was $2.1 \pm 1.1$. There were no significant differences in preoperative radiographic parameters between the groups (Table 3).

Postoperatively, in the decompression group the mean DH was $9.4( \pm 5.8) \mathrm{mm}$, FH was $19.1( \pm 5.4) \mathrm{mm}$, and FA was $127.7( \pm 53.6) \mathrm{mm}^{2}$. The improvement of each parameter after interbody fusion was as follows: $\mathrm{DH}(61.3 \%)$, FH (21.5\%), and FA (24.1\%). The mean cage height minus preoperative DH was $5.3( \pm 6.2) \mathrm{mm}$. In the nondecompression group, the mean $\mathrm{DH}$ was $12.1( \pm 4.3) \mathrm{mm}, \mathrm{FH}$

\section{TABLE 2. Procedure-related factors}

\begin{tabular}{lccc}
\hline \multicolumn{1}{c}{ Factor } & Decompression & Nondecompression & $\begin{array}{c}p \\
\text { Value }\end{array}$ \\
\hline Single-level fusion & 23 & 20 & \\
\hline 2-level fusion & 21 & 3 & \\
\hline 3-level fusion & 18 & 1 & \\
\hline Total fusion levels & 119 & 29 & 0.01 \\
\hline $\begin{array}{l}\text { Mean no. of fusion } \\
\text { levels }\end{array}$ & 1.92 & 1.21 & \\
\hline $\begin{array}{l}\text { L2-3 } \\
\text { L3-4 }\end{array}$ & 6 & 0 & \\
\hline L4-5 & 16 & 2 & 0.56 \\
\hline L5-S1 & 33 & 18 & \\
\hline $\begin{array}{l}\text { Mean cage height } \\
\text { (mm) }\end{array}$ & $15.3 \pm 7.7$ & $14.6 \pm 4.6$ & \\
\hline $\begin{array}{l}\text { Mean cage angula- } \\
\text { tion ( }{ }^{\circ} \text { ) }\end{array}$ & $15.9 \pm 7.9$ & $15.1 \pm 5.1$ & 0.48 \\
\hline
\end{tabular}

Values in the last two rows are expressed as the mean \pm SD.
TABLE 3. Preoperative radiographic measurements

\begin{tabular}{lccc}
\hline Measurement & Decompression & Nondecompression & p Value \\
\hline $\mathrm{DH}(\mathrm{mm})$ & $5.9 \pm 6.3$ & $6.2 \pm 5.3$ & 0.31 \\
\hline $\mathrm{FH}(\mathrm{mm})$ & $15.7 \pm 6.2$ & $16.2 \pm 5.9$ & 0.45 \\
\hline $\mathrm{FA}\left(\mathrm{mm}^{2}\right)$ & $103.3 \pm 52.1$ & $110.7 \pm 56.2$ & 0.46 \\
\hline $\mathrm{CCD}(\mathrm{mm})$ & $7.3 \pm 6.2$ & $7.8 \pm 6.9$ & 0.52 \\
\hline $\mathrm{FD}$ & $2.3 \pm 1.3$ & $2.1 \pm 1.1$ & 0.74 \\
\hline
\end{tabular}

Values are expressed as the mean \pm SD.

was $21.4( \pm 4.9) \mathrm{mm}$, and FA was $152.8( \pm 62.3) \mathrm{mm}^{2}$. The improvement percentages were as follows: DH (96.2\%), FH (32.1\%), and FA (36.9\%). The mean cage height minus preoperative DH was $7.5( \pm 3.5) \mathrm{mm}$. The improvement (percent change) was compared between the 2 groups, and there were significant statistical differences with regard to changes of DH, FH, and FA. In addition, the mean cage heights minus preoperative $\mathrm{DH}$ were statistically different ( $\mathrm{p}<0.05$ ) (Table 4). Because postoperative MRI was not uniformly done, postoperative CCD was not measured.

At 1 year postoperatively, the VAS leg score was $1.7( \pm$ $1.4)$ in the decompression group and $1.6( \pm 1.1)$ in the nondecompression group. The VAS back score was $2.9( \pm 2.3)$ in the decompression group and $2.8( \pm 1.7)$ in the nondecompression group. There were no significant differences between the 2 groups $(p=0.34)$.

\section{Discussion}

Traditionally, surgical treatment for symptomatic degenerative lumbar stenosis has been done by direct posterior decompression, or laminectomy. Posterior paraspinal muscle dissection, laminectomy, facetectomy, and removal of ligamentum flavum have traditionally been done to decompress the neural elements. However, the updown foraminal stenosis cannot always be alleviated with laminectomy alone; many times, $\mathrm{FH}$ and stabilization of the spinal segment are necessary to prevent further nerve compression or irritation. In addition, patient demands and increasing expectations for shorter hospital stays have led to more innovative surgical techniques such as minimally invasive surgery. To avoid iatrogenic disruption of normal anatomy, ALIF and LLIF have gained popularity, as has minimally invasive surgery. Through these approaches, spine surgeons seek to indirectly decompress the neural elements by distraction of 2 vertebrae, which leads to the opening of the neural foramen and widening of the epidural space. Furthermore, indirect decompression can result in segmental or overall realignment of the spinal column, restoring normal anatomical configuration of the neural foramen..$^{9,14}$

Excellent clinical outcomes from indirect decompression have been reported in several studies. Takahashi et al. reported on 39 patients who underwent stand-alone ALIF with more than 10 years of follow-up. More than $75 \%$ of patients showed satisfaction in long-term followup. ${ }^{19}$ No patient in their study required posterior direct decompression. In a prospective, randomized clinical study of the extreme lateral interbody fusion (XLIF) technique, 
TABLE 4. Postoperative radiographic measurements

\begin{tabular}{lcccccc}
\hline & \multicolumn{2}{c}{ Decompression } & & \multicolumn{2}{c}{ Nondecompression } & \\
\cline { 2 - 3 } Measurement & Mean \pm SD & Change $(\%)$ & & Mean \pm SD & Change (\%) & p Value \\
\hline $\mathrm{DH}(\mathrm{mm})$ & $9.4 \pm 5.8$ & 61.3 & & $12.1 \pm 4.3$ & 96.2 & 0.01 \\
\hline $\mathrm{FH}(\mathrm{mm})$ & $19.1 \pm 5.4$ & 21.5 & & $21.4 \pm 4.9$ & 32.1 & 0.01 \\
\hline $\mathrm{FA}\left(\mathrm{mm}^{2}\right)$ & $127.7 \pm 53.6$ & 24.1 & & $152.8 \pm 62.3$ & 36.9 & 0.01 \\
\hline Cage - preop DH $(\mathrm{mm})$ & $5.3 \pm 6.2$ & & $7.5 \pm 3.5$ & & 0.01 \\
\hline
\end{tabular}

a successful clinical outcome was achieved-with improvement of $41.9 \%$ in $\mathrm{DH}, 13.5 \%$ in $\mathrm{FH}, 24.7 \%$ in $\mathrm{FA}$, and $33.1 \%$ in CCD. Only 2 patients $(9.5 \%)$ required secondary additional posterior decompression. ${ }^{13}$ Sato et al. reported that 20 patients with oblique lateral interbody fusion (OLIF) showed a significant increase in DH (61\%), FA $(21 \%$ on the right, $39 \%$ on the left), and sagittal CCD (32\%). Posterior decompression was not performed in any of their patients. ${ }^{17}$

Although indirect decompression seems to be effective for many degenerative lumbar conditions, it is still unclear if all patients can be treated with indirect decompression only. Radiographic and clinical outcome studies regarding indirect decompression of central canal stenosis (as opposed to foraminal stenosis) are not as robust. Oliveira et al. concluded that central canal stenosis might be a relative contraindication in indirect decompression. ${ }^{13}$ Lang et al. insisted that direct decompression should also be performed, most specifically in patients with severe central canal stenosis, previous spine surgery, or severe multilevel disease. ${ }^{6}$ Moreover, there are very little data regarding the efficacy of indirect decompression and lateral recess stenosis. In their systemic review, Lang et al. concluded that indirect decompression could be effective for treating foraminal stenosis, but the evidence is low in assessing its efficacy in central canal and lateral recess stenosis. Kim et al. described a $60 \%$ rate of additional posterior decompression after XLIF. ${ }^{5}$ Posterior direct decompression was mostly performed in patients with insufficient $\mathrm{FH}$ restoration. In a systemic review of 1753 patients, 435 patients had a staged operation and $145(30 \%)$ of those patients underwent a posterior direct decompression because of insufficient clinical recovery after the indirect decompression. ${ }^{6}$ Central canal stenosis, significant FD and hypertrophy, immobile facets, the presence of osteophytes in the lateral recesses or foramen, calcified discs, and osteophytes arising from the posterior endplate were suggested as reasons that the indirect decompression alone was ineffective.

In our study, 62 patients (72.1\%) underwent additional posterior direct decompression. Compared with previous studies, ours showed a high rate of direct decompression. One reason for this rate is that our data included early patients, who may have had surgery before the notion that indirect decompression alone could suffice to alleviate pain. In those who had surgery in this period, all patients may have received laminectomies regardless of whether or not they were symptomatic. Another reason may have been a selection bias. Patients who had radiographic findings of severe central stenosis automatically received a decompression during their posterior operation, whether they were symptomatic or not. What is interesting, however, is that our study showed that there was no significant difference in preoperative CCD between the 2 groups; thus, radiographic central canal stenosis alone did not appear to lead to bias toward decompression.

Among the patient-related factors, the duration of symptoms was longer and VAS leg score was higher in the decompression group. This implies that not only radiological factors such as preoperative CT and MRI, but also the patient's clinical symptoms and history are important to determine the need for additional posterior decompression. Also, the rate of direct decompression was higher in patients with high VAS leg scores, which indicates either a selection bias in this patient group or that they failed to improve enough with indirect decompression alone. In addition, the mean number of fusion levels was higher in the decompression group, an indication that patients with multilevel stenosis may have had such severe symptoms that it was too difficult to localize the exact level of the pain; such patients may have undergone laminectomies simply because of the diffuse stenosis of the lumbar spine. Consistent with this, we found that severe multilevel stenosis was one of the major factors that led to direct decompression. ${ }^{13}$

Increasing $\mathrm{FH}$ and $\mathrm{FA}$ via $\mathrm{DH}$ restoration is one of the basic tenets of indirect decompression. Because of this, it would stand to reason that insertion of larger cages would lead to better clinical outcomes. However, cage height and lordosis were not significantly different between the 2 groups. In addition, other studies also showed that cage height and cage lordosis did not affect postoperative clinical outcomes..$^{5,10}$ However, a simple comparison of cage dimensions without consideration of preoperative $\mathrm{DH}$ would be shortsighted. What is important is not a direct comparison of cage heights, but rather the difference between the cage height and preoperative $\mathrm{DH}$; this corresponds to an increase in FH and FA. For instance, placing a $10-\mathrm{mm}$ cage into a $9-\mathrm{mm}$ disc space does not change $\mathrm{FH}$ as much as placing an $8-\mathrm{mm}$ cage into a 1-mm disc space. Thus, the difference between cage height and preoperative DH is important. In our study, cage height minus preoperative DH showed a greater change in the nondecompression group compared to the decompression group. In addition, postoperative $\mathrm{DH}, \mathrm{FH}$, and FA changes were significantly improved in the nondecompression group. This is also consistent with the results of previous studies that showed that improved DH, FH, and FA achieved better clinical outcomes. . $^{7,10,12,18}$

In previous reports, severe FD and hypertrophy were regarded as predictors of failure of indirect decompression. ${ }^{1,4}$ Rigid posterior elements may potentially prevent 
the distraction of the dorsal elements, and hypertrophied facets may prevent the ability to indirectly decompress the central canal. In our study, the degree of preoperative FD did not differ between the 2 groups, which argues against FD preventing indirect decompression from working. Posterior decompression may be necessary if the central canal stenosis is caused by facet hypertrophy, but in our study there was no preoperative CCD difference. Although the numbers are small, FD did not appear to affect the efficiency of indirect decompression. In addition, Malham et al. also reported that FD does not impair the amount of indirect decompression achieved, which is consistent with our observation..$^{10}$

\section{Study Limitations}

There are limitations to this study. The first is its retrospective nature, and the second is the single-institution nature of this study. In addition, because our patients from as far back as 2010 were included, clinical and radiographic indications for additional posterior direct decompression had not been clearly delineated. That is to say, it was unclear early on if indirect decompression alone was sufficient to treat these patients, and because of this uncertainty patients may have received laminectomies regardless of whether or not they had symptoms. Thus, there may have been a selection bias for laminectomy in many patients simply based on radiographic findings without clinical assessment between the stages of the anterior or lateral surgery and the posterior stage. Moreover, our numbers are small. Despite being done at a high-volume spine center, much of the work that is done is revision surgery or the case has a component of deformity. Thus, very large numbers of patients were excluded to try to obtain as clean a patient sample as possible; deformity, prior surgery, extensive multilevel reconstructive fusion surgeries, and other complex revision cases were all excluded. Thus, because of the very strict inclusion and exclusion criteria the numbers are small, but we believed that this strict exclusion criteria would be helpful to eliminate as many confounders as possible.

\section{Conclusions}

In selected patients, indirect decompression without direct decompression may be a reasonable option in treating degenerative spinal conditions if the surgery is staged. There appears to be some correlation between the need for posterior decompression and the FH, FA, difference between the cage height and preoperative $\mathrm{DH}$, duration of symptoms, and VAS leg scores. It appears that the change in the $\mathrm{DH}$ from its preoperative state provides the greatest radiographic change and is potentially the reason that a posterior decompression is not needed in certain patients. In selected patients undergoing staged surgery, indirect decompression without direct decompression may be a reasonable option in treating degenerative spinal conditions.

\section{Acknowledgments}

This work was supported by a grant from Inje University in research year 2018.

\section{References}

1. Castellvi AE, Nienke TW, Marulanda GA, Murtagh RD, Santoni BG: Indirect decompression of lumbar stenosis with transpsoas interbody cages and percutaneous posterior instrumentation. Clin Orthop Relat Res 472:1784-1791, 2014

2. Eck JC, Hodges S, Humphreys SC: Minimally invasive lumbar spinal fusion. J Am Acad Orthop Surg 15:321-329, 2007

3. Hsieh PC, Koski TR, O’Shaughnessy BA, Sugrue P, Salehi S, Ondra S, et al: Anterior lumbar interbody fusion in comparison with transforaminal lumbar interbody fusion: implications for the restoration of foraminal height, local disc angle, lumbar lordosis, and sagittal balance. J Neurosurg Spine 7:379-386, 2007

4. Isaacs RE, Sembrano JN, Tohmeh AG: Two-year comparative outcomes of MIS lateral and MIS transforaminal interbody fusion in the treatment of degenerative spondylolisthesis: part II: radiographic findings. Spine (Phila Pa 1976) 41 (Suppl 8):S133-S144, 2016

5. Kim SJ, Lee YS, Kim YB, Park SW, Hung VT: Clinical and radiological outcomes of a new cage for direct lateral lumbar interbody fusion. Korean J Spine 11:145-151, 2014

6. Lang G, Perrech M, Navarro-Ramirez R, Hussain I, Pennicooke B, Maryam F, et al: Potential and limitations of neural decompression in extreme lateral interbody fusion-a systematic review. World Neurosurg 101:99-113, 2017

7. Lee YS, Park SW, Kim YB: Direct lateral lumbar interbody fusion: clinical and radiological outcomes. J Korean Neurosurg Soc 55:248-254, 2014

8. Lestini WF, Fulghum JS, Whitehurst LA: Lumbar spinal fusion: advantages of posterior lumbar interbody fusion. Surg Technol Int 3:577-590, 1994

9. Malham GM, Ellis NJ, Parker RM, Seex KA: Clinical outcome and fusion rates after the first 30 extreme lateral interbody fusions. ScientificWorldJournal 2012:246989, 2012

10. Malham GM, Parker RM, Goss B, Blecher CM: Clinical results and limitations of indirect decompression in spinal stenosis with laterally implanted interbody cages: results from a prospective cohort study. Eur Spine J 24 (Suppl 3):339-345, 2015

11. Mobbs RJ, Sivabalan P, Li J: Minimally invasive surgery compared to open spinal fusion for the treatment of degenerative lumbar spine pathologies. J Clin Neurosci 19:829-835, 2012

12. Ohtori S, Orita S, Yamauchi K, Eguchi Y, Ochiai N, Kishida $\mathrm{S}$, et al: Mini-open anterior retroperitoneal lumbar interbody fusion: oblique lateral interbody fusion for lumbar spinal degeneration disease. Yonsei Med J 56:1051-1059, 2015

13. Oliveira L, Marchi L, Coutinho E, Pimenta L: A radiographic assessment of the ability of the extreme lateral interbody fusion procedure to indirectly decompress the neural elements. Spine (Phila Pa 1976) 35 (26 Suppl):S331-S337, 2010

14. Ozgur BM, Aryan HE, Pimenta L, Taylor WR: Extreme Lateral Interbody Fusion (XLIF): a novel surgical technique for anterior lumbar interbody fusion. Spine J 6:435-443, 2006

15. Pathria M, Sartoris DJ, Resnick D: Osteoarthritis of the facet joints: accuracy of oblique radiographic assessment. Radiology 164:227-230, 1987

16. Resnick DK, Choudhri TF, Dailey AT, Groff MW, Khoo L, Matz PG, et al: Guidelines for the performance of fusion procedures for degenerative disease of the lumbar spine. Part 7: intractable low-back pain without stenosis or spondylolisthesis. J Neurosurg Spine 2:670-672, 2005

17. Sato J, Ohtori S, Orita S, Yamauchi K, Eguchi Y, Ochiai N, et al: Radiographic evaluation of indirect decompression of mini-open anterior retroperitoneal lumbar interbody fusion: oblique lateral interbody fusion for degenerated lumbar spondylolisthesis. Eur Spine J 26:671-678, 2017

18. Silvestre C, Mac-Thiong JM, Hilmi R, Roussouly P: Compli- 
cations and morbidities of mini-open anterior retroperitoneal lumbar interbody fusion: oblique lumbar interbody fusion in 179 patients. Asian Spine J 6:89-97, 2012

19. Takahashi K, Kitahara H, Yamagata M, Murakami M, Takata K, Miyamoto K, et al: Long-term results of anterior interbody fusion for treatment of degenerative spondylolisthesis. Spine (Phila Pa 1976) 15:1211-1215, 1990

\section{Disclosures}

Dr. Mummaneni is a consultant for DePuy Spine, Globus, and Stryker. He has direct stock ownership in Spinicity/ISD. He receives support for non-study-related clinical or research effort that he oversees from NREF and AOSpine. He receives royalties from DePuy Spine, Springer Publishing, and Thieme Publishers, and he receives honoraria from Spineart. Dr. Chou is a consultant for Medtronic and Globus, and receives royalties from Globus.

\section{Author Contributions}

Conception and design: Park, Mummaneni, Mehra, Chou. Acquisition of data: Park, Mehra, Chou. Analysis and interpretation of data: Park, Mehra, Kwon, Kim, Ruan, Chou. Drafting the article: Chou. Critically revising the article: Park, Mummaneni, Mehra, Chou. Reviewed submitted version of manuscript: Park, Mummaneni, Mehra, Chou. Approved the final version of the manuscript on behalf of all authors: Park. Statistical analysis: Kwon, Kim, Ruan. Administrative/technical/material support: Chou. Study supervision: Park, Chou.

\section{Correspondence}

Daehyun Park: Inje University Busan Paik Hospital, Busan, Korea.spineparkdaehyun@gmail.com. 